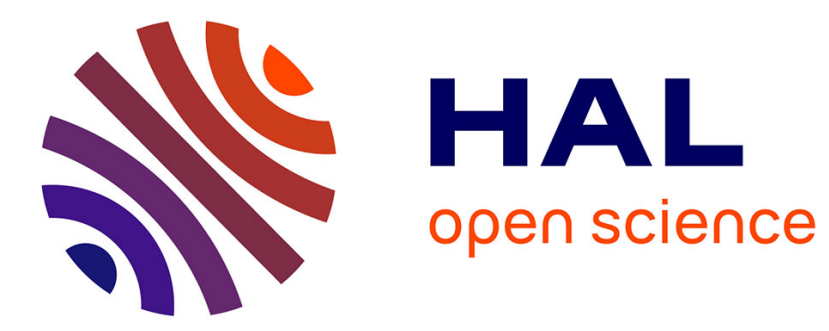

\title{
Coupling length phase matching for third-order frequency downconversion in dual core fibers
}

\author{
Ivan Biaggio, Virginie Coda, Germano Montemezzani
}

\section{To cite this version:}

Ivan Biaggio, Virginie Coda, Germano Montemezzani. Coupling length phase matching for third-order frequency downconversion in dual core fibers. Frontier in Optics / Laser Science 2015, Optical Society of America, Oct 2015, San Jose, United States. pp.FM1F.2, 10.1364/fio.2015.fm1f.2 . hal-01244422

\section{HAL Id: hal-01244422 \\ https://hal.science/hal-01244422}

Submitted on 21 Apr 2020

HAL is a multi-disciplinary open access archive for the deposit and dissemination of scientific research documents, whether they are published or not. The documents may come from teaching and research institutions in France or abroad, or from public or private research centers.
L'archive ouverte pluridisciplinaire HAL, est destinée au dépôt et à la diffusion de documents scientifiques de niveau recherche, publiés ou non, émanant des établissements d'enseignement et de recherche français ou étrangers, des laboratoires publics ou privés. 


\title{
Coupling Length Phase Matching for Third-Order Frequency Downconversion in Dual Core Fibers
}

\author{
I. Biaggio ${ }^{\mathrm{a}}$, V. Coda ${ }^{\mathrm{b}}$, G. Montemezzani ${ }^{\mathrm{b}}$ \\ ${ }^{a}$ Lehigh University, Bethlehem Pennsylvania, USA \\ ${ }^{b}$ Université de Lorraine and CentraleSupélec, LMOPS, EA 4423, F-57070 Metz, France \\ biaggio@lehigh.edu
}

\begin{abstract}
The coupling between parallel waveguides leads to a quasi-phase matching effect that allows to obtain phase matching for third-order down conversion and other third-order processes in silica fibers. Several phase matching conditions are found.

OCIS codes: (190.4223) Nonlinear wave mixing; (230.7370) Waveguides.
\end{abstract}

\section{Third-order interaction of three waves in parallel waveguides}

The coupling constants between closely spaced parallel waveguides can play the role of the missing wavevectors for phase-matched nonlinear optical interaction of waves of different wavelength, with the coupling length determining the phase matching conditions. This Coupling Length Phase Matching (CLPM) process can be used to obtain quasiphase phase matching in the absence of any modulation of the linear or nonlinear optical properties of the material. Using CLPM it therefore becomes possible to realize various phase matched third-order frequency conversion processes in a system like a dual core waveguide.

A general framework for CLPM has been developed in Ref. 1. Here we discuss a quasi-degenerate four wave mixing process where two waves at a shorter wavelength mix to create a wave at a longer wavelength. Assuming that the frequencies of the three waves are $\omega_{3}>\omega_{2}>\omega_{1}$ and that $\omega_{1}=2 \omega_{2}-\omega_{3}$, the normalized amplitudes of the three waves in one of the waveguides can then be modeled using the standard coupled wave equations:

$$
\begin{aligned}
& \frac{\partial}{\partial z} A_{3}^{(a)}=i \chi A_{1}^{(a)^{*}}\left[A_{2}^{(a)}\right]^{2} e^{-i \Delta k z}+i \kappa_{3} A_{3}^{(b)} \\
& \frac{\partial}{\partial z} A_{2}^{(a)}=2 i \chi A_{1}^{(a)} A_{2}^{(a)^{*}} A_{3}^{(a)} e^{i \Delta k z}+i \kappa_{2} A_{2}^{(b)} \\
& \frac{\partial}{\partial z} A_{1}^{(a)}=i \chi\left[A_{2}^{(a)}\right]^{2} A_{3}^{(a)^{*}} e^{-i \Delta k z}+i \kappa_{1} A_{1}^{(b)}
\end{aligned}
$$

where the $A_{\mathrm{i}}$ with superscript " $(a)$ " describe the normalized amplitudes of the waves with frequency $\omega_{\mathrm{i}}$ in waveguide " $a$ ", while those with superscript " $(b)$ " describe the normalized amplitudes of the same waves in waveguide " $b$ ". Here the $\chi$ is an effective third-order nonlinear coefficient for the three-wave interaction in one of the waveguides, the $\kappa_{\mathrm{i}}$ are the coupling constants for each of the waves, and $\Delta k=k_{3}-2 k_{2}+k_{1}$ is the wavevector mismatch caused by refractive index dispersion.

\section{Phase matched third-order downconversion in parallel waveguides}

Analysis of the coupled wave equations delivers conditions to obtain CLPM. For the example of the generation, by two strong pump waves of a wave at frequency $\omega_{1}=2 \omega_{2}-\omega_{3}$, the amplitude of the generated wave will grow linearly with distance when the coupling constants between the waveguides are such that $\pm \Delta k=\kappa_{1}-2 \kappa_{2}+\kappa_{3}$, or when when $\pm \Delta k=\kappa_{1}-\kappa_{3}$ for any value of $\kappa_{2}$ (for other possibilities, see Ref. 1). The latter of the two conditions given here is particularly interesting because it only requires to match the difference of the coupling constants between the waves with the largest difference in frequency to the wavevector mismatch, while the coupling constant for the other wave can have any value. Fig. 1 shows both the prediction of the analytical calculation for the growth of the amplitude of the signal wave, and the results of a full numerical solution of the above system of equations. 

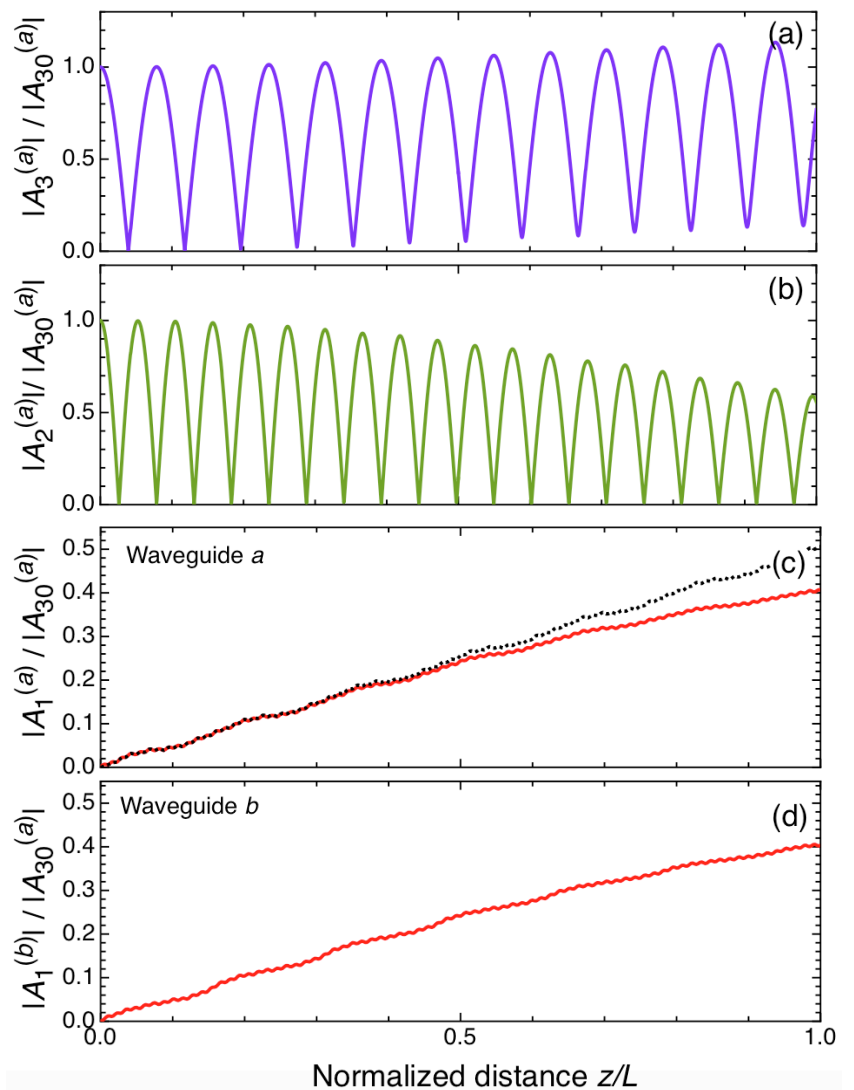

Fig. 1. Spatial evolution of the amplitudes of the interacting waves in the case of third-order frequency down conversion, $\omega_{1}=2 \omega_{2}-\omega_{3}$ for the CLPM condition $\Delta k=\kappa_{1}-\kappa_{3}$ in parallel waveguides of length $L$. Panels (a) and (b) give the amplitudes, in waveguide a, of the pump waves at frequency $\omega_{3}$ and $\omega_{2}$, respectively. The generated wave amplitude at the frequency $\omega_{1}$ is shown for both waveguides in (c) and (d), respectively. The solid curves are all in the pump depletion regime. The black dotted curve in (c) corresponds to the analytical solution from Ref. 1 in the undepleted regime.

Thanks to this CLPM process, an equal signal wave amplitude builds up in both waveguides a and $\mathrm{b}$. In contrast to the pump waves, the generated wave does not oscillate between the waveguides. Also, for longer distances the pump wave at the largest frequency can be fully depleted, with its energy going into the amplification of the second pump wave and the creation of the signal wave, corresponding to the maximum possible conversion efficiency for this frequency conversion process. Possible implementations of this CLPM process in dual core optical fibers will be discussed at the meeting. Finally, the same CLPM formalism can be used to analyze, and find phase matching condition for, many other third-order effects. A discussion of CLPM for third-harmonic generation in parallel waveguides can be found in Ref. 2.

[1] I. Biaggio, V. Coda, G. Montemezzani, "Coupling length phase matching for nonlinear optical frequency conversion in parallel waveguides", Phys. Rev. A 90, 043816-1-11 (2014).

[2] T. Huang, P. P. Shum, X. Shao, T. Lee, Z. Wu, H. Li, T. Wu, M. Zhang, X. Q. Dinh, G. Brambilla, "Coupling-length phase matching for efficient third-harmonic generation based on parallel-coupled waveguides", Opt. Lett. 40, 894-897 (2015). 